\title{
Cloning and genomic characterization of sytdep, a new synaptotagmin XIV-related gene
}

\author{
M. Javier Herrero-Turrión ${ }^{\mathrm{a}}$, Mitsunori Fukuda ${ }^{\mathrm{b}}$ and Faustino Mollinedo ${ }^{\mathrm{a}, *}$
}

${ }^{a}$ Centro de Investigación del Cáncer, Instituto de Biología Molecular y Celular del Cáncer, Consejo

Superior de Investigaciones Científicas (C.S.I.C.)-Universidad de Salamanca, Campus Miguel de Unamuno, E-37007 Salamanca, Spain

${ }^{\mathrm{b}}$ Fukuda Initiative Research Unit, The Institute of Physical and Chemical Research (RIKEN), 2-1 Hirosawa, Wako, Saitama 351-0198, Japan

Correspondence address:

Faustino Mollinedo

Centro de Investigación del Cáncer

Instituto de Biología Molecular y Celular del Cáncer

CSIC-Universidad de Salamanca

Campus Miguel de Unamuno

E-37007 Salamanca

Spain

Phone: (+34) 923-294806

Fax: (+34) 923-294795

E-mail: fmollin@usal.es 


\section{FOOTNOTES}

Abbreviations used: bp, base pair; HRP, horseradish peroxidase; DMSO, dimethyl sulfoxide; ORF, open reading frame; PMN, polymorphonuclear neutrophil; RT-PCR, reverse transcriptionpolymerase chain reaction; SNARE, soluble $N$-ethylmaleimeide-sensitive factor (NSF) attachment protein (SNAP) receptor; syt, synaptotagmin; sytdep, synaptotagmin XIV-derived protein; SDS, sodium dodecyl sulfate; UTR, untranslated region.

*Corresponding author. Fax: +34 923294795.

E-mail address: fmollin@usal.es (F. Mollinedo).

The nucleotide sequence data for human sytdep (synaptotagmin XIV-derived protein) reported in this work has the GenBank accession no. $\underline{\mathbf{A Y 9 5 4 5 1 3}}$. 


\begin{abstract}
We have identified a new human gene coined sytdep (synaptotagmin XIV-derived protein) in human neutrophils. Sytdep encodes a 188-amino acid sequence with a $21.435 \mathrm{kDa}$ deduced molecular mass, showing $75 \%$ identity to human synaptotagmin (syt) XIV. Human neutrophils express sytdep, but not syt XIV. Sytdep was upregulated during HL-60 neutrophil differentiation. Sytdep gene is located in human chromosome 4 and contains a unique exon, whereas syt XIV gene, located in chromosome 1 , comprises 10 exons with 9 introns. Mouse genome did not contain sytdep. The N-terminal region of sytdep shows no homology with any known protein and, unlike synaptotagmin XIV isoforms, sytdep shows a unique C-terminal C2B domain. Polyclonal antibodies against the C2B domain of syt XIV recognized sytdep as a $27 \mathrm{kDa}$ protein in human neutrophils. Genomic analyses suggest that human sytdep could derive from a retrotranslocation of a syt XIV transcript into chromosome 4.
\end{abstract}

Keywords: alternative splicing, genomic characterization, gene expression, C2 domain, synaptotagmin XIV-derived gene, human neutrophils, cloning. 


\section{Introduction}

Synaptotagmins (syts) are a family of membrane proteins featured by an N-terminal transmembrane domain (type I membrane topology), two C-terminal tandem $\mathrm{C} 2$ domains (C2A and C2B), which are responsible for binding calcium and phospholipids, and a short conserved Cterminal sequence, which may be crucial for docking to the plasma membrane and correct folding of the C2B domain [1-4]. Syts and SNARE [soluble $N$-ethylmaleimeide-sensitive factor (NSF) attachment protein (SNAP) receptor] proteins are likely to represent the minimal protein complement for $\mathrm{Ca}^{2+}$-triggered exocytosis [5]. In vertebrates, 16 isoforms of syt have been identified [6], some of which appear to function as $\mathrm{Ca}^{2+}$ sensors that couple $\mathrm{Ca}^{2+}$ to membrane fusion in vivo and in vitro $[7,8]$. The most abundant isoform, syt $\mathrm{I}$, appears to function as a $\mathrm{Ca}^{2+}$ sensor that triggers the rapid exocytosis of synaptic vesicles from neurons, but the functions of the remaining syt isoforms are ill-defined. Syts are known to be evolutionarily and functionally well conserved genes and thought to be derived from common ancestral genes. Distinct variants generated by alternative splicing have been reported, including transmembrane exon skipping and syt VII splice variants that differentially regulate synaptic vesicle recycling [9-12].

The partial sequence of a putative chr415 syt gene, so-called by Craxton [13], has been suggested to be a human orthologue of mouse syt XIV in the human genome [14]. In the present report, we have completed the sequence of chr415 syt gene and found by cloning, sequencing and chromosomal localization that this gene is different from syt XIV and encodes a novel protein that shows a high amino acid identity with that of syt XIV. We have coined this new gene as synaptotagmin XIV-derived protein (sytdep) as it is phylogenetically related to syt XIV. In addition, we have found that human polymorphonuclear neutrophils (PMNs) express high levels of sytdep, but not syt XIV. 


\section{Materials and methods}

Cell culture and neutrophil isolation. The human acute myeloid leukemia HL-60 cell line was grown in RPMI-1640 mediun supplemented with 10\% (v/v) heat-inactivated fetal calf serum, 2 $\mathrm{mM}$ glutamine, 100 units $/ \mathrm{ml}$ penicillin, and $24 \mu \mathrm{g} / \mathrm{ml}$ gentamicin at $37{ }^{\circ} \mathrm{C}$ in a humidified atmosphere of air/ $\mathrm{CO}_{2}$ (19/1). Neutrophil differentiation of HL-60 cells was induced by adding 1.3 $\%$ (v/v) dimethyl sulfoxide (DMSO) as previously described [15]. The human astrooligodendroglioma (grade II/III) GOS-3 cell line was grown in Dulbecco's modified Eagle's medium (DMEM) supplemented with 10\% (v/v) heat-inactivated fetal calf serum, $2 \mathrm{mM}$ glutamine, 100 units $/ \mathrm{ml}$ penicillin, and $24 \mu \mathrm{g} / \mathrm{ml}$ gentamicin at $37^{\circ} \mathrm{C}$ in a humidified atmosphere of air/ $\mathrm{CO}_{2}$ $(19 / 1)$.

Neutrophils were obtained from fresh human peripheral blood by dextran sedimentation and centrifugation on Ficoll-Hypaque (Pharmacia LKB Biotechnology, Uppsala, Sweden), followed by hypotonic lysis of residual erythrocytes as previously described [16], and the final cell preparation contained more than $99 \%$ neutrophils as assessed by Wright-Giemsa staining. Postnuclear neutrophil extracts were prepared and processed for Western blotting as previously described [17].

Nucleic acid isolation and reverse transcription-polymerase chain reaction (RT-PCR). Both genomic DNA and total RNA were purified from the different cell types used in this work using the DNAzol genomic DNA isolation reagent and the TRIZOL reagent (Gibco BRL, Gaithersburg, MD), respectively. RNA preparations were carefully checked by gel electrophoresis and found to be free of DNA contamination. Total RNA $(5 \mu \mathrm{g})$, primed with oligo-dT, was reverse-transcribed into cDNA at $37^{\circ} \mathrm{C}$ for $2 \mathrm{~h}$ using the first-strand cDNA synthesis kit (Amersham Biosciences, Piscataway, NJ) according to the manufacturer's instructions in a $20-\mu 1$ volume, and stored at $-20^{\circ} \mathrm{C}$ until use. A $25-\mu 1$ PCR mixture contained 500 ng of cDNA template or genomic DNA, 20 pmol of 
each primer, $0.2 \mathrm{mM}$ dNTPs, $1.5 \mathrm{mM} \mathrm{MgCl}_{2}$ and 5 units of Taq DNA polymerase (Roche, Basel, Switzerland). PCR reactions were performed in a GeneAmp PCR system model 9600 (PerkinElmer, Norwalk, CT). The primers used are listed in Table 1. Amplification of human $\beta$-actin (GenBank accession no. NM 001101) (5'-AATATGGCACCACACCTTCTACA-3' and 5'CGACGTAGCACAGCTTCTCCTTA-3') was used as an internal and loading control. PCR amplification was as follows: 1 cycle at $95^{\circ} \mathrm{C}$ for $5 \mathrm{~min}$ as an initial denaturation step, then denaturation at $95^{\circ} \mathrm{C}$ for $30 \mathrm{~s}$, annealing at $53-63^{\circ} \mathrm{C}$ for $30 \mathrm{~s}$, and extension at $72^{\circ} \mathrm{C}$ for $90 \mathrm{~s}(30$ cycles), followed by further incubation for $15 \mathrm{~min}$ at $72^{\circ} \mathrm{C}(1$ cycle). PCR conditions were shown to be at the linear phase of amplification to assess a semiquantitative analysis. PCR products were electrophoresed on $2 \%$ agarose gels in $1 \mathrm{X}$ TAE (40 mM Tris-acetate, $1 \mathrm{mM}$ EDTA, pH 8.0) and visualized by ethidium bromide staining.

Cloning and sequencing. PCR products were either extracted from the agarose gel using the Concert $^{\mathrm{TM}}$ kit (Gibco BRL) or cloned into the $\mathrm{pCR}^{\circledR} 2.1$ vector, using the TA-TOPO cloning kit (Invitrogen, San Diego, CA) following the manufacturer's indications, and sequenced in an ABI PRISM $^{\circledR} 3100$ Genetic Analyzer (Applied Biosystems, Foster City, CA). DNA sequencing was performed on both strands from 10 independent cDNA clones. Distinct genomic and cDNA sequences were aligned by ClustalW program [18]. Potential full-length cDNAs were sequenced, analysed, and searched against nucleotide and protein databases by using BLAST programs (BLASTn, tBLASTn, BLASTp).

Protein biotinylation and immunoprecipitation. Cells $\left(20 \times 10^{6}\right)$ were lysed with 50-200 $\mu 1$ of lysis buffer (20 mM HEPES pH 7.5, 10 mM EGTA, 40 mM $\beta$-glycerophosphate, 1\% NP-40, 2.5 $\mathrm{mM} \mathrm{MgCl}_{2}, 2 \mathrm{mM}$ orthovanadate, $1 \mathrm{mM}$ DTT, $1 \mathrm{mM}$ phenylmethylsulfonyl fluoride, $20 \mu \mathrm{g} / \mathrm{ml}$ aprotinin, $20 \mu \mathrm{g} / \mathrm{ml}$ leupeptin), and centrifuged at $12000 \mathrm{rpm}$ for $20 \mathrm{~min}$ at $4^{\circ} \mathrm{C}$. Solubilized proteins (5-30 $\mu \mathrm{g})$ were biotinylated with $200 \mu \mathrm{l}$ of $10 \mathrm{mM}$ Sulfo-NHS-Biotin (Sulfo-Succinimidyl-6- 
(biotinamido) hexanoate; EZ-Link ${ }^{\mathrm{TM}}$ Sulfo-NHS-LC-Biotin; Pierce Biotechnology, Rockford, IL) for $30 \mathrm{~min}$ at room temperature with constant rotation. Then, these biotinylated lysates were precleared with protein A-Sepharose as previously described [19]. Affinity-purified rabbit polyclonal antibody raised against the C2B domain of syt XIV fused to GST [14], and P3X63 myeloma culture supernatant (a kind gift of Dr. F. Sánchez-Madrid, Hospital de La Princesa, Madrid, Spain), used as a negative control, were coupled to protein A-Sepharose beads (Amersham Biosciences) by incubation for $2 \mathrm{~h}$ at $4^{\circ} \mathrm{C}$ with constant rotation. These beads were pelleted, washed twice with lysis buffer, and incubated with the supernatant from the preclearing step for $2 \mathrm{~h}$ at $4^{\circ} \mathrm{C}$ with constant rotation. Sepharose beads were then pelleted and washed 5 times with lysis buffer. Then, $20 \mu \mathrm{l}$ SDS sample buffer $(50 \mathrm{mM}$ Tris-HCl pH 6.8, $100 \mathrm{mM}$ DTT, 2\% SDS, 0.1\% bromophenol blue, $10 \%$ glycerol) were added, and samples were subjected to SDS-15\% PAGE under reducing conditions and immunoblotted [20]. Biotynilated proteins were visualized with streptavidin-horseradish peroxidase (HRP) conjugate (diluted 1/1000 in TBST: Tris-buffered saline (TBS) -50 mM Tris- $\mathrm{HCl} \mathrm{pH} 8.0,150 \mathrm{mM} \mathrm{NaCl}$ - containing 0.05\% Tween 20), using an ECL detection system (Amersham Biosciences).

\section{Results and discussion}

\section{Identification and molecular characterization of sytdep}

A putative syt gene, named chr415 syt (GenBank/EMBL accession number, AJ303368), was identified and partially sequenced in a previous study by Craxton [13]. We cloned and sequenced chr415 syt in human neutrophils and found its identity to chr415 syt, with only one nucleotide difference (Fig. 1A). Recently, this gene was assigned to syt XIV [14] by sequence comparison. However, we have found evidences that questioned this assumption. First, comparison of the partial nucleotide and amino acid sequence of chr415 syt with that corresponding to syt XIV showed differences both in DNA and protein sequences (Fig. 1), although amino acid sequence comparison 
of chr415 syt with the six isoforms of syt XIV indicated that the protein encoded by this gene showed a strong homology with isoform 2 of syt XIV (Fig. 1B). Secondly, we found that human neutrophils expressed chr415 syt, but not syt XIV (data not shown), using RT-PCR and a wide array of PCR primers covering the whole sequences of syt XIV and chr415 syt. On these grounds, we asked whether these two sequences could correspond to two different genes. Using the BLASTn program we analyzed the chromosome location of both genes, aligning all known syt XIV isoforms and chr415 syt sequence versus the full human genome. Surprisingly, two distinct gene loci for syt $X I V$ and chr415 syt were found in the human chromosomal positions 1q32.2 and 4q13.2, respectively.

In order to characterize the nucleotide sequences of both the genomic locus and transcript corresponding to the gene defined by the partial chr415 syt sequence, we carried out a BLASTn analysis of the partial cDNA sequence known of chr415 syt in the human chromosome 4 region (positions from 8932396 to 8929693 ), which led to a prediction of 2584 bp for the full-length chr415 syt cDNA (Fig. 2A). By RT-PCR assays we found a cDNA sequence that contained a single ORF encoding a protein of 188 amino acids with a deduced molecular mass of $21.435 \mathrm{kDa}$ (Fig. 2A). These results extended and completed the partial nucleotide sequence of chr415 syt. We also found one nucleotide difference at position 479, leading to a Thr-Met change at residue 97 (Fig. 2A). We coined the name sytdep (synaptotagmin XIV-derived protein) for this new gene (GenBank accession no. $\underline{\mathbf{A Y 9 5 4 5 1 3}}$ ). The predicted full-length sytdep cDNA contained a 189-bp 5'untranslated region (5'-UTR), a 564-bp ORF, and a 1831-bp 3'-UTR (Fig. 2A). The rather long length of the 3' untranslated sequence might be similar to that highly conserved of rat and human syt I gene, arguing for conserved functions in non-coding regions. The sytdep cDNA showed high identity with three clones of human chromosome 4 (GenBank accession nos. $\underline{\mathbf{A C 0 9 6 7 2 7}}$, $\underline{\mathrm{BC} 041902}$, and $\underline{\mathrm{AJ617629}})$.

The amino acid sequence of human sytdep showed $75 \%$ identity to synaptotagmin XIV. The primary sequence of sytdep showed a 57\% identity to the human syt XIV-related protein (strep14, 
a.k.a. syt XVI), and 20-24\%, 10-19\% and 12\% identity to other syt isoforms, syt-like proteins (slps) and slp homologue lacking $\mathrm{C} 2$ domain protein (slac2), respectively. On the other hand, the $\mathrm{N}$ terminal region (24 amino acids) of sytdep did not show any significant homology with any known protein domain. A physiological role for the N-terminal region of Syt in neutransmission has been recently reported [21]. This might suggest a specific role for sytdep that remains to be elucidated.

Unlike most synaptotagmin XIV isoforms (Fig. 1B) that contain two C2 domains, C2A and $\mathrm{C} 2 \mathrm{~B}$, sytdep contains a single $\mathrm{C} 2 \mathrm{~B}$ domain at the $\mathrm{C}$-terminus, and thereby sytdep behaves as a single C2 domain-containing protein. C2 domains are conserved motifs of $~ 135$ amino acids that often serve as $\mathrm{Ca}^{2+}$-binding domains [22]. The $\mathrm{Ca}^{2+}$-binding sites of the $\mathrm{C} 2$ domains are formed by five conserved acidic residues present in two flexible loops (loops 1 and 3) [23, 24]. However, sytdep as well as syt XIV [14] lack the above acidic residues, suggesting that sytdep, like syt XIV, is a $\mathrm{Ca}^{2+}$-independent $\mathrm{C} 2$ protein. Unlike syts that contain the conserved C-terminus WHXL motif, which may be crucial for docking to the plasma membrane and correct folding of the $\mathrm{C} 2 \mathrm{~B}$ domain [25], sytdep lacks this motif, being substituted by a WQAL motif (Fig. 1B and 2A) of uncertain function.

Like other syts, sytdep protein lacks a signal peptide, and it lacks apparently a transmembrane domain. Sytdep contains two hydrophobic regions of approximately 8 and 16 amino acids (Fig. 2, A and B), which could be sufficient for a putative transmembrane domain, but the location of these regions in the $\mathrm{C} 2 \mathrm{~B}$ domain make this option particularly implausible as $\mathrm{C} 2 \mathrm{~B}$ domains do not act as transmembrane domains. Three potential N-glycosilation sites (Asn-XaaSer/Thr; 60-62, 141-143, and 158-160), one potential O-glycosilation (Thr-Xaa-Ser, 39-41) site, and a number of potential Ser, Thr and Tyr phosphorilation sites $(12 / 2 / 2)$ were found in the deduced amino acid sequence of sytdep (Fig. 2A). No potential N-myristoylation or prenylation sites were detected, but three Cys residues at the $\mathrm{N}$-terminal domain might be fatty-acylated as it happens in some syts [26]. 


\section{Genomic structures of human syt XIV and sytdep}

The gene structures of human syt XIV and sytdep were determined by database searching and PCR approaches. The human syt XIV and sytdep genes were mapped to chromosome 1 and 4, spanning 226,054 and 2,584 bp, respectively. Syt XIV gene consisted of 10 exons with 9 introns of various lengths, whereas sytdep gene showed a unique exon (Fig. 3). The Syt XIV exon 4 encoded the transmembrane domain, and the $\mathrm{C} 2 \mathrm{~A}$ and $\mathrm{C} 2 \mathrm{~B}$ domains were encoded by exon 7 and exons 810 , respectively. Syt $X I V$ exon 3 is not translated as it occurs with other human syt genes containing 5' non-coding exons [13]. Six different syt XIV transcripts have been sequenced, namely: syt XIV, syt XIV-1, syt XIV-2, syt XIV-3, syt XIV-4, syt XIV-5 (GenBank accession nos. NM 153262,

$\underline{\mathbf{A J 6 1 7 6 2 3}}, \underline{\mathbf{A J 6 1 7 6 2 4}}, \underline{\mathbf{A J 6 1 7 6 2 5}}, \underline{\mathbf{A J 6 1 7 6 2 6}}, \underline{\mathbf{A J 6 1 7 6 2 7}}$ ), with ORFs encoding sequences of 555, 457, 517, 265, 503 and 416 amino acids, respectively (Figs. 1B and 3). As shown in Fig. 3, we found that these syt XIV isoforms result from alternative splicing. In syt XIV and syt XIV-1, exon 1 encodes the initial 4 amino acids and the first nucleotide of the 5th amino acid; exons 2 and 4 encode 15 and 56 amino acids, respectively. In syt XIV-2 and -3, exon 4 encodes the initial 37 amino acids, and the putative transmembrane domain is incomplete due to the fact that this exon is likely skipped by alternative splicing at the mRNA level. In all these syt XIV isoforms, exons 5, 6, 7 and 8 encode 72, 92, 149 (or 64 in syt XIV-3) and 63 amino acids, respectively. So far, the initial amino acids of both syt XIV-4 and -5 isoforms remain unidentified, and thereby exons 5 and 6 encode the first known 69 and 64 amino acids, respectively. The so-called syt XIV homology domain [14] is encoded by exon 5. Finally, exons 9 and 10 encode 27 and 103 or 102 (due to an amino acid deletion in syt XIV-4 and -5) amino acid residues, respectively. Thus, alternative splicing of the upstream sequence of transmembrane region (exons 1 and 2) and the C2A and C2B domains (exons 7 and 9, respectively) give rise to the distinct isoforms. Table 2 shows the distinct exon and intron compositions as well as the exon-intron junctions of the human syt XIV gene, containing the highly conserved sequences for RNA splicing in higher eukaryotes, namely GT at 
the 5' splice site (donor site) and AG at the 3' splice site (acceptor site) [27], except exons 7 and 9 that show in addition GC and TG as intron 5'- and 3'-splice donor and acceptor sites.

Using BLAST search from the human genome database and DNA sequencing we mapped sytdep locus in chromosome 4 containing the exons 1, 2, 3, 4, 8 and 10 of syt XIV with no introns (Fig. 3). Due to the high similarity between sytdep and syt XIV, it could be envisaged that the human sytdep gene might originate from a syt XIV transcript derived of chromosome 1, which was retrotranslocated to a genomic region of chromosome 4. Thus, as shown in Fig. 3, the sytdep genomic locus could result from a fusion of exons 1, 2, 3, 4, 8 and 10 of syt XIV gene.

Interestingly, the mouse genome did not contain sytdep by database searching. In addition, we were unable to identify sytdep in mouse brain cDNA by RT-PCR (data not shown). Thus, the above putative retrotranslocation leading to sytdep apparently occurred in human, but not in mouse.

\section{Sytdep expression in human neutrophils}

Because sytdep and synaptotagmin XIV isoforms showed a high degree of homology, we next asked whether these genes could be differentially expressed. We designed specific primers for the distinct syt XIV isoforms and sytdep, and carried out RT-PCR experiments with different pairs of primers (Table 1 and Fig. 4), in peripheral blood human neutrophils, human leukemia HL-60 cells, neutrophil-differentiating-HL60 cells, and human astro-oligodendroglioma GOS-3 cell line. The HL-60 cell line has been widely used as a cell culture model to study different molecular aspects of human neutrophils, as it acquires many biochemical and functional characteristics of mature neutrophils following treatment with DMSO for 4 days [15]. As shown in Fig. 4, sytdep was highly expressed in mature peripheral blood neutrophils, and resulted upregulated during neutrophil differentiation of HL-60 cells. However, no syt XIV expression was detected. GOS-3 cells expressed both sytdep and syt XIV isoform. Cloning and sequencing of the syt XIV amplified band indicated that this amplicon corresponded to syt XIV isoform 2. 
We next investigated whether the sytdep transcript was translated into protein in human neutrophils where we found a high sytdep mRNA expression. Due to the high identity (84\%) between the C2B domains of syt XIV and sytdep, we assumed that a polyclonal antibody against the C2B domain of syt XIV could detect the C2B-containing sytdep protein. By immunoprecipitating biotinylated cell protein extracts with the above polyclonal antibody, we observed an immunoreactive band of $\sim 27 \mathrm{kDa}$ in the neutrophil extract (Fig. 5A), which could well correspond to the expected size of sytdep protein. The use of protein biotinylation avoided the use of secondary antibodies and thereby the putative interference with the $55-\mathrm{kDa}$ heavy and $25-\mathrm{kDa}$ light immunoglobulin chains. In addition, the above anti-C2B antibody recognized a band of $\sim 27$ $\mathrm{kDa}$ in the postnuclear extract of human neutrophils by immunoblotting when high amounts of extract protein were used (Fig. 5B). This molecular mass is higher than the predicted molecular mass $(21.435 \mathrm{kDa})$ based on the ORF of the cloned sytdep cDNA, and could be in part due to posttranslational modifications.

Because we have found that SNARE proteins are involved in human neutrophil exocytosis $[17,19,28]$, and syts have been reported to interact with SNARE proteins [5, 29-31], it is tempting to suggest a putative role for sytdep in the secretory response of human neutrophils where sytdep mRNA is particularly highly expressed. The unique major functional domain present in sytdep is the $\mathrm{C} 2 \mathrm{~B}$ domain, which has been involved in binding to other $\mathrm{C} 2 \mathrm{~B}$ domains, accessory proteins independent of divalent cations and phospholipids, as well as in exocytosis [32-34]. The polybasic Lys-rich region of $\mathrm{C} 2 \mathrm{~B}$ domain has been implicated in the binding to phosphatidylinositol $(4,5)$ bisphosphate in the absence of $\mathrm{Ca}^{2+}[35,36]$. On these grounds, it could be envisaged that the $\mathrm{C} 2 \mathrm{~B}$ domain of the new gene sytdep might be involved in membrane trafficking in human neutrophils via binding to phosphoinositides. The expression of sytdep in human neutrophils might increase the number of exocytosis-related genes, including SNARE proteins $[17,19,28]$, expressed in human neutrophils. 


\section{Acknowledgements}

We are indebted to Javier de la Riva and Alberto de Luis for their assistance with the BLAST programs. We thank the Blood Bank of the Hospital Universitario of Salamanca for blood supply. This work was supported by grants from the Fondo de Investigación Sanitaria and European Commission (FIS-FEDER 04/0843, 02/1199, 01/1048), Ministerio de Educación y Ciencia (SAF2005-04293), Fundación de Investigación Médica Mutua Madrileña (FMM), Fundación “la Caixa" (BM05-30-0), and Junta de Castilla y León (CSI04A05).

\section{References}

[1] B. Marqueze, F. Berton, and M. Seagar, Synaptotagmins in membrane traffic: which vesicles do the tagmins tag?, Biochimie 82 (2000) 409-420.

[2] M. Fukuda, J. E. Moreira, V. Liu, M. Sugimori, K. Mikoshiba, and R. R. Llinas, Role of the conserved WHXL motif in the $\mathrm{C}$ terminus of synaptotagmin in synaptic vesicle docking, Proc Natl Acad Sci U S A 97 (2000) 14715-14719.

[3] E. R. Chapman, Synaptotagmin: a $\mathrm{Ca}(2+)$ sensor that triggers exocytosis?, Nat Rev Mol Cell Biol 3 (2002) 498-508.

[4] T. C. Sudhof, Synaptotagmins: why so many?, J Biol Chem 277 (2002) 7629-7632.

[5] W. C. Tucker, T. Weber, and E. R. Chapman, Reconstitution of Ca2+-regulated membrane fusion by synaptotagmin and SNAREs, Science 304 (2004) 435-438.

[6] M. Craxton, Synaptotagmin gene content of the sequenced genomes, BMC Genomics 5 (2004) 43.

[7] M. Yoshihara, and E. S. Montana, The synaptotagmins: calcium sensors for vesicular trafficking, Neuroscientist 10 (2004) 566-574.

[8] E. Hui, J. Bai, P. Wang, M. Sugimori, R. R. Llinas, and E. R. Chapman, Three distinct kinetic groupings of the synaptotagmin family: candidate sensors for rapid and delayed exocytosis, Proc Natl Acad Sci U S A 102 (2005) 5210-5214.

[9] M. Fukuda, and K. Mikoshiba, A novel alternatively spliced variant of synaptotagmin VI lacking a transmembrane domain. Implications for distinct functions of the two isoforms, J Biol Chem 274 (1999) 31428-31434.

[10] M. Craxton, and M. Goedert, Alternative splicing of synaptotagmins involving transmembrane exon skipping, FEBS Lett 460 (1999) 417-422.

[11] M. Fukuda, Y. Ogata, C. Saegusa, E. Kanno, and K. Mikoshiba, Alternative splicing isoforms of synaptotagmin VII in the mouse, rat and human, Biochem J 365 (2002) 173-180.

[12] T. Virmani, W. Han, X. Liu, T. C. Sudhof, and E. T. Kavalali, Synaptotagmin 7 splice variants differentially regulate synaptic vesicle recycling, Embo J 22 (2003) 5347-5357.

[13] M. Craxton, Genomic analysis of synaptotagmin genes, Genomics 77 (2001) 43-49.

[14] M. Fukuda, Molecular cloning, expression, and characterization of a novel class of synaptotagmin (Syt XIV) conserved from Drosophila to humans, J Biochem (Tokyo) 133 (2003) 641-649. 
[15] F. Mollinedo, A. M. Santos-Beneit, and C. Gajate, The human leukemia cell line HL-60 as a cell culture model to study neutrophil functions and inflammatory responses, in Animal cell culture techniques, in Clynes, M., (Ed.), Springer-Verlag, Heidelberg, Germany, 1998, pp. 264-297.

[16] B. Martin-Martin, S. M. Nabokina, P. A. Lazo, and F. Mollinedo, Co-expression of several human syntaxin genes in neutrophils and differentiating HL-60 cells: variant isoforms and detection of syntaxin 1, J Leukoc Biol 65 (1999) 397-406.

[17] F. Mollinedo, B. Martin-Martin, J. Calafat, S. M. Nabokina, and P. A. Lazo, Role of vesicleassociated membrane protein-2, through q-soluble $\mathrm{N}$ - ethylmaleimide-sensitive factor attachment protein receptor/r-soluble $\mathrm{N}$ - ethylmaleimide-sensitive factor attachment protein receptor interaction, in the exocytosis of specific and tertiary granules of human neutrophils, J Immunol 170 (2003) 1034-1042.

[18] J. D. Thompson, D. G. Higgins, and T. J. Gibson, CLUSTAL W: improving the sensitivity of progressive multiple sequence alignment through sequence weighting, position-specific gap penalties and weight matrix choice, Nucleic Acids Res 22 (1994) 4673-4680.

[19] B. Martin-Martin, S. M. Nabokina, J. Blasi, P. A. Lazo, and F. Mollinedo, Involvement of SNAP-23 and syntaxin 6 in human neutrophil exocytosis, Blood 96 (2000) 2574-2583.

[20] S. Nabokina, G. Egea, J. Blasi, and F. Mollinedo, Intracellular location of SNAP-25 in human neutrophils, Biochem Biophys Res Commun 239 (1997) 592-597.

[21] A. Nakhost, G. Houeland, V. F. Castellucci, and W. S. Sossin, Differential regulation of transmitter release by alternatively spliced forms of synaptotagmin I, J Neurosci 23 (2003) 62386244.

[22] J. Bai, and E. R. Chapman, The C2 domains of synaptotagmin--partners in exocytosis, Trends Biochem Sci 29 (2004) 143-151.

[23] J. Rizo, and T. C. Sudhof, C2-domains, structure and function of a universal Ca2+-binding domain, J Biol Chem 273 (1998) 15879-15882.

[24] J. Ubach, Y. Lao, I. Fernandez, D. Arac, T. C. Sudhof, and J. Rizo, The C2B domain of synaptotagmin I is a Ca2+-binding module, Biochemistry 40 (2001) 5854-5860.

[25] M. Fukuda, A. Yamamoto, and K. Mikoshiba, Formation of crystalloid endoplasmic reticulum induced by expression of synaptotagmin lacking the conserved WHXL motif in the C terminus. Structural importance of the WHXL motif in the C2B domain, J Biol Chem 276 (2001) 41112 41119.

[26] M. Fukuda, E. Kanno, Y. Ogata, and K. Mikoshiba, Mechanism of the SDS-resistant synaptotagmin clustering mediated by the cysteine cluster at the interface between the transmembrane and spacer domains, J Biol Chem 276 (2001) 40319-40325.

[27] M. R. Green, Pre-mRNA splicing, Annu Rev Genet 20 (1986) 671-708.

[28] F. Mollinedo, Human neutrophil granules and exocytosis molecular control, Inmunologia 22 (2003) 340-358.

[29] C. Rickman, D. A. Archer, F. A. Meunier, M. Craxton, M. Fukuda, R. D. Burgoyne, and B. Davletov, Synaptotagmin interaction with the syntaxin/SNAP-25 dimer is mediated by an evolutionarily conserved motif and is sensitive to inositol hexakisphosphate, J Biol Chem 279 (2004) 12574-12579.

[30] J. Bai, C. T. Wang, D. A. Richards, M. B. Jackson, and E. R. Chapman, Fusion pore dynamics are regulated by synaptotagmin*t-SNARE interactions, Neuron 41 (2004) 929-942.

[31] S. K. Rao, C. Huynh, V. Proux-Gillardeaux, T. Galli, and N. W. Andrews, Identification of SNAREs involved in synaptotagmin VII-regulated lysosomal exocytosis, J Biol Chem 279 (2004) 20471-20479.

[32] M. Fukuda, J. E. Moreira, F. M. Lewis, M. Sugimori, M. Niinobe, K. Mikoshiba, and R. Llinas, Role of the C2B domain of synaptotagmin in vesicular release and recycling as determined by specific antibody injection into the squid giant synapse preterminal, Proc Natl Acad Sci U S A 92 (1995) 10708-10712. 
[33] R. B. Sutton, J. A. Ernst, and A. T. Brunger, Crystal structure of the cytosolic C2A-C2B domains of synaptotagmin III. Implications for $\mathrm{Ca}(+2)$-independent snare complex interaction, $\mathrm{J}$ Cell Biol 147 (1999) 589-598.

[34] I. Fernandez, D. Arac, J. Ubach, S. H. Gerber, O. Shin, Y. Gao, R. G. Anderson, T. C. Sudhof, and J. Rizo, Three-dimensional structure of the synaptotagmin 1 C2B-domain: synaptotagmin 1 as a phospholipid binding machine, Neuron 32 (2001) 1057-1069.

[35] G. Schiavo, Q. M. Gu, G. D. Prestwich, T. H. Sollner, and J. E. Rothman, Calcium-dependent switching of the specificity of phosphoinositide binding to synaptotagmin, Proc Natl Acad Sci U S A 93 (1996) 13327-13332.

[36] B. Mehrotra, J. T. Elliott, J. Chen, J. D. Olszewski, A. A. Profit, A. Chaudhary, M. Fukuda, K. Mikoshiba, and G. D. Prestwich, Selective photoaffinity labeling of the inositol polyphosphate binding C2B domains of synaptotagmins, J Biol Chem 272 (1997) 4237-4244.

[37] J. Kyte, and R. F. Doolittle, A simple method for displaying the hydropathic character of a protein, J Mol Biol 157 (1982) 105-132. 


\section{FIGURE LEGENDS}

FIG. 1. Chr415 syt and syt XIV encode different proteins. (A) The nucleotide sequence of human polymorphonuclear neutrophil (PMN) chr415 syt cDNA is compared with the nucleotide sequences of chr415 syt and syt XIV cDNAs. Human neutrophil chr415 syt cDNA was obtained by RT-PCR using distinct pairs of primers shown in Table 1. Dashes have been introduced to maximize sequence identity. Asterisks show positions in the alignment that are perfectly conserved. (B) The partial amino acid sequence of chr415 syt gene is compared with the complete amino acid sequences of the six syt XIV isoforms. The putative transmembrane region (TM) (in bold), syt XIV homology domain (in bold), and the $\mathrm{C} 2 \mathrm{~A}$ and $\mathrm{C} 2 \mathrm{~B}$ domains (in black boxes) are indicated. Asterisks indicate the Cys residues that can be fatty-acylated. $\boldsymbol{\Delta}$ indicates the Lys residues (polybasic region) that mediate binding to phosphoinositides. The WHXL motif (in gray boxes) is replaced by the WQAL motif in chr415 syt. Arrowheads above the alignment indicate the positions of the alternative splicing sites. Dashes have been introduced to maximize sequence identity. Total number of amino acids is indicated at the end of each sequence.

FIG. 2. Nucleotide and deduced amino acid sequences of human sytdep. (A) Nucleotides are numbered in the 5' to $3^{\prime}$ direction and the predicted amino acid sequence is shown in single-letter code below the nucleotide sequence. Nucleotides and amino acids are numbered on the right. Inframe termination codons are marked by $\frac{\mathrm{L}}{7}$. The $\mathrm{C} 2 \mathrm{~B}$ domain includes from C-35 to R-188. Two hydrophobic regions are boxed. \# indicates the Cys residues that may be fatty-acylated. A number of potential Ser $(*)$, Thr (II) and Tyr $(\Delta)$ phosphorilation sites are labeled. Lys residues $(\boldsymbol{\Delta}$, polybasic region) that can mediate binding to phosphoinositides are also indicated. The WHXL motif present in syt XIV is replaced by the underlined WQAL motif. Putative polyadenylation signal (ATTAAA motif) are also underlined. The nucleotide and predicted amino acid sequences of human sytdep are available from GenBank accession no. $\underline{\mathbf{A Y 9 5 4 5 1 3}}$. (B) Hydrophobicity profile of human sytdep. This profile was obtained according to [37] and shows two hydrophobic regions.

FIG. 3. Genomic organization and transcription of the human syt XIV and sytdep genes. Exons and introns are represented by boxes and solid bars. Exons are numbered (1 to 10) on top of each box. Exons encoding the transmembrane domain (TM), the $\mathrm{C} 2$ domains, and the non-coding (untranslated) regions are represented by black, hatched, and dotted boxes, respectively. The number of amino acids encoded by each transcript is shown. The exon/intron boundaries are 
indicated by arrows, and the numbers above the arrows describe position in the codon at which the coding sequence is separated by an intron $(0=$ at the codon junction; 1 and $2=$ after the first codon and the second codon position, respectively). Broken lines indicate the corresponding exons of the syt XIV and sytdep genes. The numbers on top of the unique exon of sytdep indicate the exons of syt $X I V$ gene locus which lead to this monoexonic gene. Chromosome location of syt XIV and sytdep genes are indicated in parenthesis. Letters below the exons stand for primers used in gene cloning from Table 1.

FIG. 4. Differential expression of syt XIV and sytdep in human cells. Total RNA was purified from human peripheral blood neutrophils, GOS-3 cells as well as HL-60 cells and neutrophildifferentiated HL-60 cells following a 4-day DMSO incubation [HL-60(DMSO)]. The expression of sytdep and syt XIV was assessed by RT-PCR. Primers used, corresponding to those listed in Table 1, are shown in parenthesis. Amplification of $\beta$-actin was used as an internal control. The PCR products were electrophoresed and stained with ethidium bromide. The size of each amplified PCR fragment is shown. Data shown are representative of three separate experiments.

FIG. 5. Sytdep protein in human neutrophils. (A) Biotinylated neutrophil extracts were immunoprecipitated with rabbit polyclonal antibody against the C2B domain of syt XIV or P3X63 myeloma supernatant, as a negative control, and immunoprecipitates were subjected to SDS-PAGE and immunoblotted with streptavidin-HRP. (B) Different amounts of postnuclear extract proteins from resting human neutrophils were run on SDS-PAGE and analyzed by immunoblotting using the above anti-C2B domain antibody. The molecular mass of the immunoreactive band is indicated on the right. Data shown are representative of three separate experiments. 
Table 1

Primers used for sytdep and syt XIV cloning

Primer location in the corresponding GenBank sequences of human origin are indicated.

\begin{tabular}{|c|c|c|c|c|c|}
\hline Type of primer & $\begin{array}{c}\text { Primer } \\
\text { name }\end{array}$ & Sequence & Position & $\begin{array}{c}\text { GenBank } \\
\text { accession no. }\end{array}$ & Gene name \\
\hline Forward & $\bar{A}$ & CAGTTGGTGCGGTCCATG & $121342-121359$ & AC096727 & Clone chr4 \\
\hline " & " & " & $6-23$ & AJ617623 & Syt XIV-1 \\
\hline " & B & СCTGATGCTGCTTCTTTTTCTC & $121199-121220$ & AC096727 & Clone chr4 \\
\hline " & " & " & $125-146$ & NM_153262 & Syt XIV \\
\hline " & " & " & $181-206$ & AJ617623 & Syt XIV-1 \\
\hline “ & “ & " & $288-309$ & AJ617624 & Syt XIV-2 \\
\hline " & “ & " & $321-342$ & AJ617625 & Syt XIV-3 \\
\hline " & C & CAGGATGACAGTGGTTCTCC & $519-538$ & NM_153262 & Syt XIV \\
\hline " & " & " & $539-558$ & AJ6̄17623 & Syt XIV-1 \\
\hline " & " & " & $682-701$ & AJ617624 & Syt XIV-2 \\
\hline " & " & " & $715-734$ & AJ617625 & Syt XIV-3 \\
\hline " & “ & " & $272-291$ & AJ617626 & Syt XIV-4 \\
\hline " & " & " & $31-50$ & AJ617627 & Syt XIV-5 \\
\hline$"$ & D & CCAGAAATTCT(C/T)ATT(A/G)GCCTGC & $120999-121020$ & AC096727 & Clone chr4 \\
\hline " & " & " & $15-36$ & AJ303368 & chr415 syt \\
\hline “ & $"$ & $"$ & $1263-1284$ & NM_153262 & Syt XIV \\
\hline " & " & " & $1283-1304$ & AJ6̄17623 & Syt XIV-1 \\
\hline “ & “ & $"$ & $1483-1304$ & AJ617624 & Syt XIV-2 \\
\hline " & " & " & $1188-1209$ & AJ617625 & Syt XIV-3 \\
\hline “ & “ & $"$ & $1016-1037$ & AJ617626 & Syt XIV-4 \\
\hline " & " & " & $775-796$ & AJ617627 & Syt XIV-5 \\
\hline Reverse & $E$ & TCATCGTGACTCTAGCAACG & $120604-120624$ & AC096727 & Clone chr4 \\
\hline " & " & " & 1666-1685 & NM_153262 & Syt XIV \\
\hline " & " & " & $1825-1848$ & AJ6̄17624 & Syt XIV-2 \\
\hline$"$ & $"$ & $"$ & $1587-1610$ & AJ617625 & Syt XIV-3 \\
\hline " & " & " & $1493-1516$ & AJ617626 & Syt XIV-4 \\
\hline " & $"$ & $"$ & $1231-1254$ & AJ617627 & Syt XIV-5 \\
\hline " & $\mathrm{F}$ & GGAGAACCACTGTCATCCTG & $539-558$ & NM_153262 & Syt XIV \\
\hline " & " & $"$ & $682-701$ & AJ6̄17624 & Syt XIV-2 \\
\hline " & " & $"$ & $715-734$ & AJ617625 & Syt XIV-3 \\
\hline " & " & " & $272-291$ & AJ617626 & Syt XIV-4 \\
\hline " & " & " & $31-50$ & AJ617627 & Syt XIV-5 \\
\hline " & G & TTCATCGTGACTCTAGCAACG & $120603-120623$ & AC096727 & Clone chr4 \\
\hline$"$ & $"$ & " & $412-432$ & AJ303368 & chr415 syt \\
\hline " & " & " & $1652-1668$ & NM_153262 & Syt XIV \\
\hline " & " & " & $1666-1686$ & AJ $\overline{6} 17623$ & Syt XIV-1 \\
\hline " & " & " & $1829-1849$ & AJ617624 & Syt XIV-2 \\
\hline " & " & " & $1591-1611$ & AJ617625 & Syt XIV-3 \\
\hline " & " & " & $1497-1517$ & AJ617626 & Syt XIV-4 \\
\hline " & " & $"$ & $1235-1255$ & AJ617627 & Syt XIV-5 \\
\hline
\end{tabular}




\section{Table 2}

Exon-intron junctions in the human syt XIV gene

Exon and intron sequences are in upper and lower case letters, respectively. Start and stop codons are labeled in bold. The gene contains the typical gt and ag at the 5' splice site (donor site) and 3' splice site (acceptor site) for RNA splicing, required for intron removal. The variant $\mathrm{gc}$ and tg dinucleotides for 5'- and 3'-splice donor and acceptor sites are underlined. Sizes in bp of introns and exons are indicated.

\begin{tabular}{|c|c|c|c|c|}
\hline Exon & Exon size (bp) & Exon-intron junctions & Intron & Intron size (bp) \\
\hline 1 & 45 & ......ATCATGG.. & 1 & 14431 \\
\hline 2 & 47 & aatagGTGGAG........GGAAAGgtaatt & 2 & 297 \\
\hline 3 & 205 & tcagAATCTG..........GGAAAGgtaatt & 3 & 60374 \\
\hline 4 & 169 & ctctagTATC....TTGATGCT......TTGTAAgtatcg & 4 & 7236 \\
\hline 5 & 215 & aaatagATAATT........ATGAAGgtaaga & 5 & 73067 \\
\hline 6 & 272 & tatcagGAAACT........CCTGAAgtaagt & 6 & 5418 \\
\hline 7 & 450 & tcttagGATATG........CATTCTgtgagt & 7 & 55258 \\
\hline $7^{\prime}$ & 179 & tcttagGATATG........CTCATGgcaagt & $7^{\prime}$ & 55531 \\
\hline 8 & 190 & ttacagGGCTGT.........CACCCAgtgagt & $\begin{array}{l}8 \\
8^{\prime}\end{array}$ & $\begin{array}{l}3509 \\
3488\end{array}$ \\
\hline 9 & 57 & tgtcagATGGAC.......TCCGAGgtgagt & 9 & 1451 \\
\hline $9^{\prime}$ & 78 & ttactgCTTTCC.......TCCGAGgtgagt & & \\
\hline 10 & $>314$ & ctttagATACAT.....GAGTCATGA... & & \\
\hline
\end{tabular}


Figure 1A

Herrero-Turrión, M.J.

PMN Chr415 syt Chr415 syt

PMN Chr415 syt Chr415 syt

Syt XIV

PMN Chr415 syt Chr415 syt

PMN Chr415 syt Chr415 syt

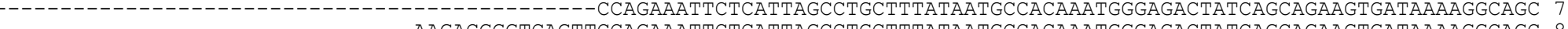
TGTAGTGAAGTACATCCTCATGTCAGTCTCTTAAGACGGTCAGTTCCAGAAATTCTCATTAGCCTGCTTTATAATGCCACAAATGGGAGACTATCAGCAGAAGTGATAAAAGGCAGC 86 等

CACTTAAAAAATTGGGCAGCAAACAGACCACCCAATACATATGTTAAGTTAACTCTACGGAAATCCATGGATCAAGAGATGTCCAAATGCAAGATATCCATCCGCAGAGGGCGGCCAAAT 190 CACTTAAAAAATTGGGCAGCAAACAGACCACCCAATACATATGTTAAGTTAACTCTACGGAAATCCACGGATCAAGAGATGTCCAAATGCAAGATATCCATCCGCAGAGGGCGGCCAAAT 206 CACTTCAAAAATT GGCAGCAAACAGACCACCCAATACATATGTAATIACTCTACTGAATICCATGGGTCAAGAGATGTCCAAATGCAAGACATCCATCCGCAGAGGGCAGCCAAAT 1440

CCAGTATACAAGGAAACTTTTGTTTTCAAAGTGACCCTATTTCAGCTTTCTCATGTGACACTCATGCTGTCTGTGTATAACAAAAGCAGCATGAGAAGAAA---GATGATAGGCTGGATT 307 CCA CCAGTATATAAGGAAACTTTTGTCTTTCAAGTGGCCCTATTTCAGCTTTCTGATGTGACACTCATACTGTCTGTGTATAACAAACGCAGCATGAAAAGAGAAGAGATGATAGGCTGGATT

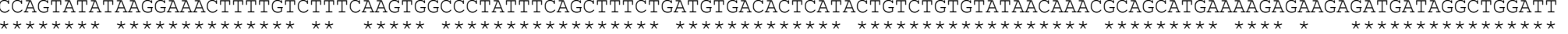

TATTTAGGTCTCAACAGCTCTGGAGAAGAA---CTCAATCACTGGACTGAAATGAAAGAGTCAAAAGGACGGCAAGTACGTAGATGGCAGGCGTTGCTAGAGTCACGATGAA TATTTAGGTCTCAACAGCTCTGGAGAAGAA---CTCAATCACTGGACTGAAATGAAAGAGTCAAAAGGACGGCAAGTACGTAGATGGCAGGCGTTGCTAGAGTCACGATGA

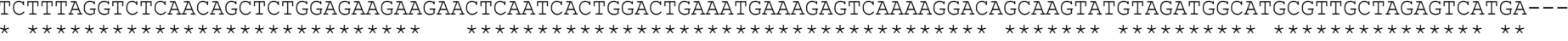


Figure 1B

Herrero-Turrión, M.J.

\section{TM}

Syt XIV

homology domain

V * * $V$ * $\vee$ (1)

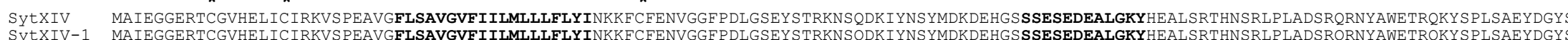

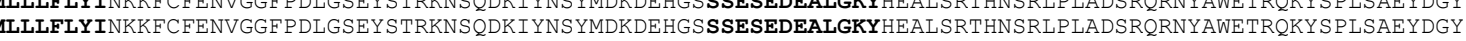

SytXIV-3 SytX-5

(

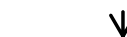
$\vee$

\section{$\bigvee$}

$\begin{array}{lll}\text { SYLXIV } & \text { SEASIDEGNCIQRMRRTPPLDELQPPPYQDDSGSPHLSCTPSEIGDSKCEFSHCSNSPRCSYNKCPSEGSTGHEIESFHNKGYEEDVPSDSTAVLSPEDMSAQGSSSQLPKPEDPEP }\end{array}$

SYTXIV-2 SEASIDEGNCIQRMRRTPPLDELQPPPYQDDSGSPHLSCTPSEIGDSKCEFSHCSNSPRCSYNKCPSEGSTGHEIESFHNKGYEEDVPSDSTAVLSPEDMSAQGSSSQLPKPFDPEP

SYXIV-3 SEASIDEGNCIQRMRRTPPLDELQPPPYQDDSGSPHLSCTPSE IGDSKCEFSHCSNSPRCS YNKCPSEGSTGHEIESFHNKGYEEDVPSDSTAVLSPEDMSAQGSSSQLPKPFDPE PE

SYtXIV-5 -------------PLDELQPPPYQDDSGSPHLSCTPSEIGDSKCEFSHCNNSPRCYNKCPSEGSTGHEIESFHNGYEEDVPSDSTAVLSPEDMSAQGSSSQLPKPFDPEPEAKYGTLDVTFDYDSOEOKLLVI 
Figure 2A

Herrero-Turrión, M.J.

cagttggtgcggtccatggtgagctcatcatggcgattgaaggtggagaga gaacctgtggagtacatgaact tacctgttt tagaaaagtatctccagagg cagttgggtttttgtcagctgtttgggtgtttattatcctgatgctgct tc

ttttctctatattaataagcagttctgttttgaaaATGTTGGAGGGCTTC $\begin{array}{llllll}M & \mathbf{L} & \mathbf{E} & \mathbf{G} & \mathbf{F}\end{array}$

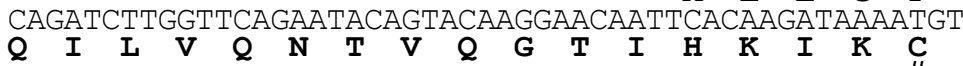
GTCTGTGACTCCCAAATGAGCGTGTCAGAAATGTCTTGTAGTGAAAGTACA $\begin{array}{lllllllllllllllll}\mathrm{V} & \mathrm{C} & \mathrm{D} & \mathbf{S} & \boldsymbol{Q} & \mathbf{M} & \mathbf{S} & \mathrm{V} & \mathbf{S} & \mathbf{E} & \mathbf{M} & \mathbf{*} & \mathbf{H} & \mathbf{S} & \mathbf{E} & \mathbf{S} & \mathbf{T}\end{array}$

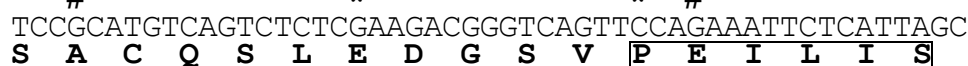

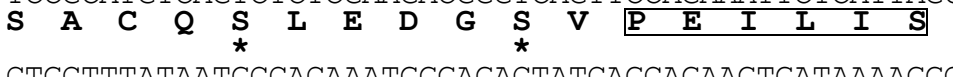

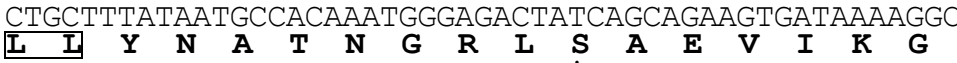
AGCCACTTAAAAAATTGGGCAGCAAACAGACCACCCAATACATATGTTAAG $\begin{array}{llllllllllllllllll}\mathbf{S} & \mathbf{H} & \mathbf{L} & \mathbf{K} & \mathbf{N} & \mathbf{W} & \mathbf{A} & \mathbf{A} & \mathbf{N} & \mathbf{R} & \mathbf{P} & \mathbf{P} & \mathbf{N} & \mathbf{T} & \mathbf{Y} & \mathbf{V} & \mathbf{K}\end{array}$

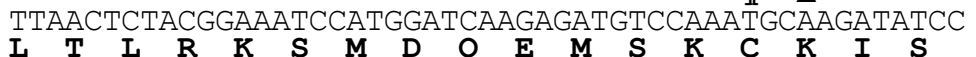

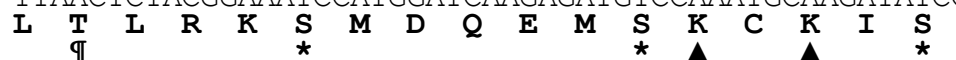
ATCCGCAGAGGGCGGCCAAATCCAGTATACAAGGAAACTTTTGTTTTCAAA

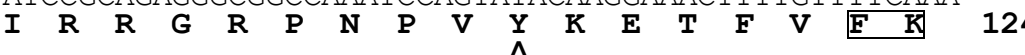
GTGACCCTATTTCAGCTTTCTCATGTGACACTCATGCTGTCTGTGTATAAC $\begin{array}{lllllllllllllllll}\mathbf{V} & \text { T } & \text { L } & \text { F } & \text { Q } & \text { L } & \text { S } & \text { H } & \text { V } & \text { T } & \text { L } & \text { M } & \text { L } & \text { S } & \text { V } & \mathbf{Y} & \mathbf{N}\end{array}$ AAAAGCAGCATGAGAAGAAAGAGATAGGCTGGATTTATTTAGGTCTCAAC $\begin{array}{lllllllllllllllll}\mathbf{K} & \mathbf{S} & \mathbf{S} & \mathbf{M} & \mathbf{R} & \mathbf{R} & \mathbf{K} & \mathbf{M} & \mathbf{I} & \mathbf{G} & \mathbf{W} & \mathbf{I} & \mathbf{Y} & \mathbf{L} & \mathbf{G} & \mathbf{L} & \mathbf{N}\end{array}$ AGCTCTGGAGAAGAACTCAATCACTGGACTGAAATGAAAGAGTCAAAAGGA $\begin{array}{llllllllllllllllll}\mathbf{S} & \mathbf{S} & \mathbf{G} & \mathbf{E} & \mathbf{E} & \mathbf{L} & \mathbf{N} & \mathbf{H} & \mathbf{W} & \mathbf{T} & \mathbf{E} & \mathbf{M} & \mathbf{K} & \mathbf{E} & \mathbf{S} & \mathbf{K} & \mathbf{G} & 175\end{array}$ CGGCAAGTACGTAGATGGCAGGCGTTGCTAGAGTCACGATGAatacaataa $\begin{array}{llllllllllllll}\mathbf{R} & \mathbf{Q} & \mathbf{V} & \mathbf{R} & \mathbf{R} & \mathbf{W} & \mathbf{Q} & \mathbf{A} & \mathbf{L} & \mathbf{L} & \mathbf{E} & \mathbf{S} & \mathbf{R} & \mathbb{T} \\ & \mathbf{W} & & \end{array}$ tctaccaagtcoccattgraagagctgttctttgaagatcatattcaacc tctaccaagtcgccattggaagagctgttctttgaagaatcatattcaacc
ttt taccaaatgcttaagt ctatggaaagacatctaatactgagata aatgaagaaatatgtgtatctgatagagcttgtttgggaaactgagaaac gtacattatcattgttaaactaacagtcctccagaaatttaataagatgtt tttgatttgaagttaattttaatttagcaaagagccggtaattttatgaa aaatcaaattataagtgattttaaaaccagagttttagtcgcaatataa ttttaatatcactctacatattatttataaaacatagtttggccagtccct ggtgtttgtaatgttctttaatatgaaaaagtagtcctccaaccctatcot aagtcatatctaatggcgaaggotttcagtcacattgaaaattgttttat tcagacatgttccttttgtgcacttagtttcattgtgcctcagttcctctc tatagcactaaatctaagtgcagacaagcattcgttttcatacaggaatgt ttttaatatgcaaagtcactgtgctggtcccttgcaagtctttagacaggt tgtactgtagaactacgtaactttctgttgaaagcacttcctgtattcttg tatttcaatgtaggaagctagtagagcaagact ttactttaaaatttctt cagtgattgactcttcaaaattgcagtaatgtgaaatacatttttttt acaaactgaaacacagcagataagctgtagaaatgaaaacgattcaat tt taattttctgctctgagtatttagtaaccaacactgcctaaagcaggta gcatccaaaraagaaactattctctctctaaatct cactcttacttcaa tttacatttgtgatataaagactatgcagttctcagtttaaatcggaacat catgttaaaacagttctgagattccttacgaagtttccaataacttgtga ctagactttatgaaatttacggataaagttcttcaacatgatgttatcttg tgccttcatgtaagttgaatttgctcatacggcttgaaagttgtatttgc aaattaagccttcgatttt tataaatgcaacgattcctcagaacagtgtc gcaagatctttatttcctccgaagtatgtaaaagttgtatgatgtgctaat tttgtaaatggcaagtcactttcatttgtttttatatttagaaactctaat taatcaggaatattataagctgttttctttataattttgcttcttacctaa tgtatcattttatgcatatactttattaaatagagtatgttttatatatat taaaatagtttcttttttctccttctcatttctagttcaaatagacaaaa acatactatttaccagttactaaaagcagtatatcattgctcctagtccc aaaaagtactatatattattataaactagaacttgttattaccataataa aaaagaccgtgaaattctgtattttttcatttaaaaatgrcagctctatg cattcatacacatgaattataagaaaaatacaaagotatattggatga atgaggtttgagaatgtgttttacagggctgcattaaagggaaaaattcat attt tattgttacatcaatgagctttctccaggatttttacaataaacgag taggaattagaacctgaatcaaatggcgagagat

51 22

306

56

$73^{408}$

459

107 
Figure 2B

Herrero-Turrión, M.J.

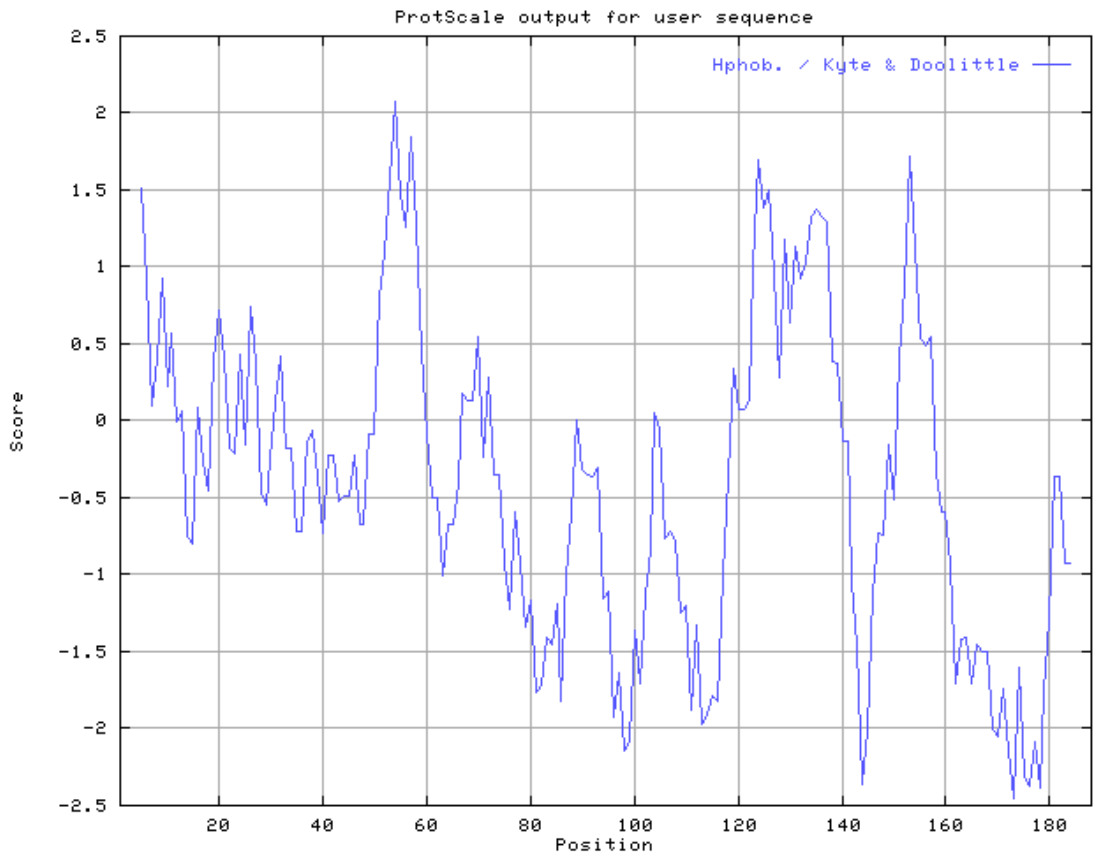


Figure 3

Herrero-Turrión, M.J.

\section{Syt XIV isoforms}

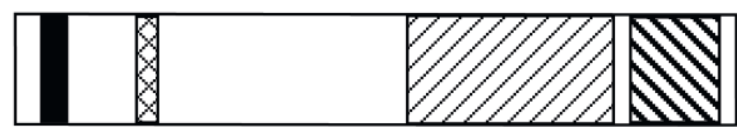

Syt XIV-1; 457 aa
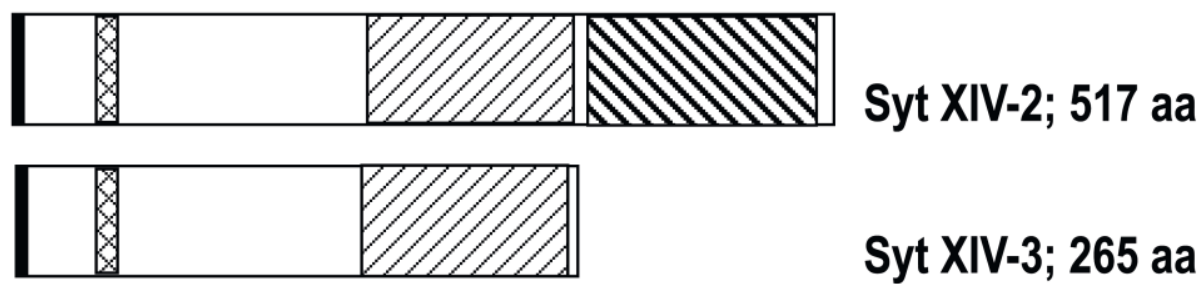

Syt XIV-3; 265 aa



Syt XIV-4; 503 aa

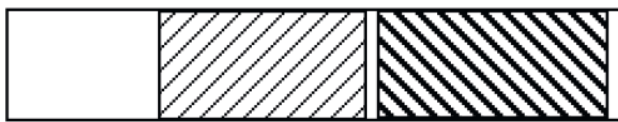

Syt XIV-5; 416 aa
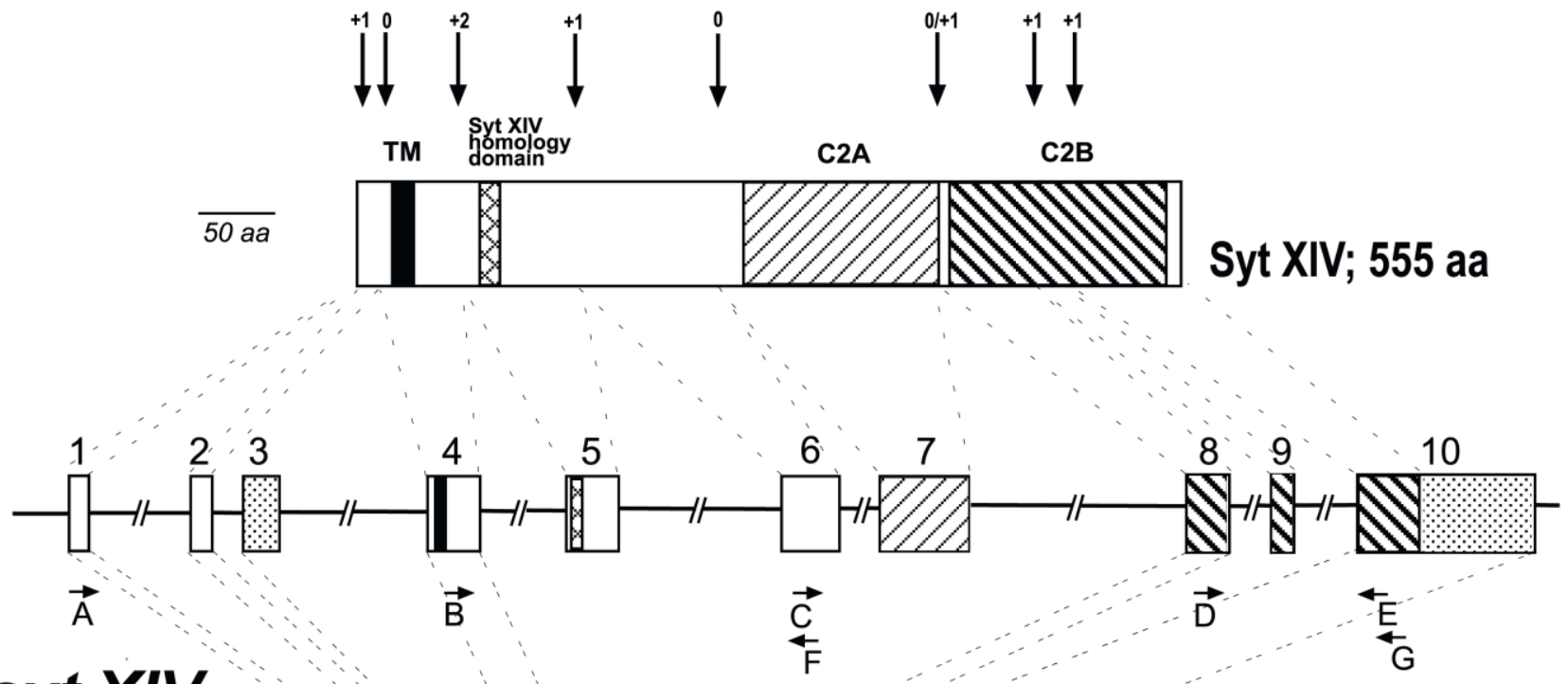

syt XIV

(chr 1)

$\overline{100 b p}$

sytdep

$\begin{array}{ll:lll}\text { (chr 4) } & \vec{A} & \vec{B} & \vec{D} & \stackrel{E}{\mathrm{G}}\end{array}$

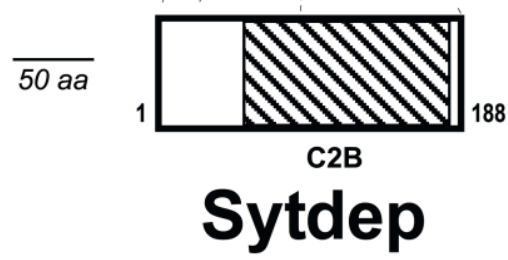


Figure 4

Herrero-Turrión, M.J.
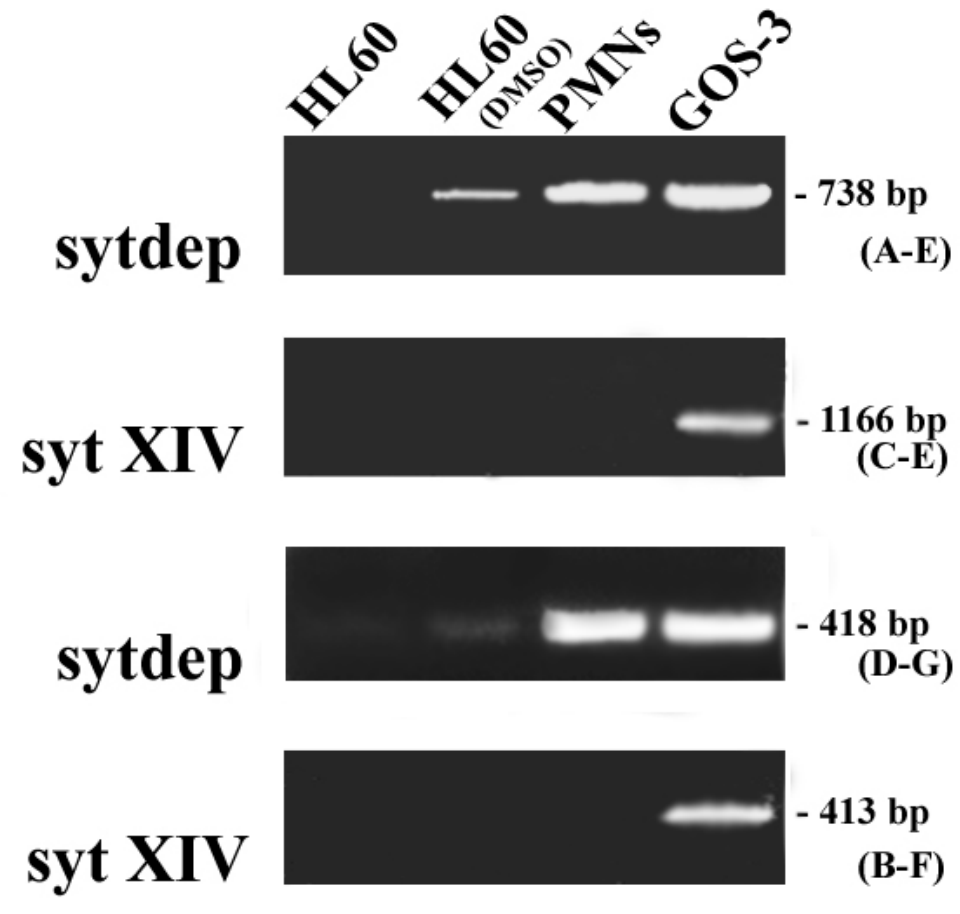

$\beta$-Actin 
Figure 5

Herrero-Turrión, M.J.

A

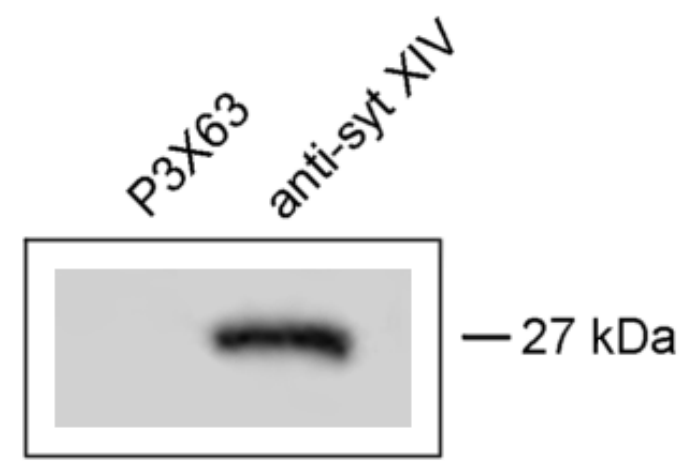

B

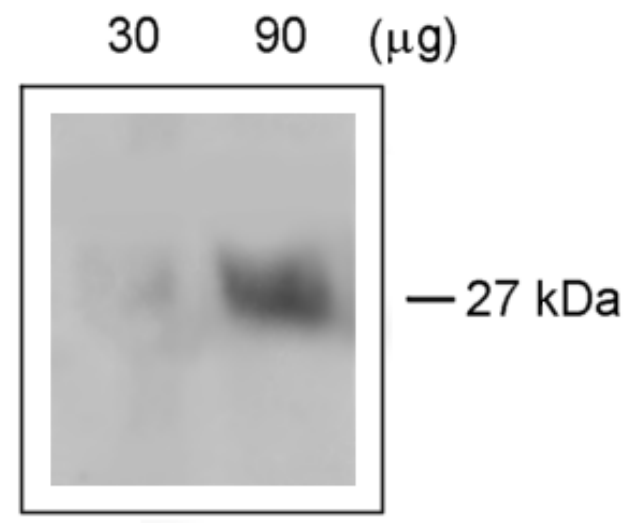

